\title{
Transient atrial fibrillation precipitated by hypoglycaemia: two case reports
}

\author{
A. Collier, D.M. Matthews, R.J. Young and B.F. Clarke \\ Diabetic and Dietetic Department, Royal Infirmary, Edinburgh, EH3 9YW, UK.
}

\begin{abstract}
Summary: We describe two insulin-dependent diabetic females who presented with severe hypoglycaemia associated with atrial fibrillation which reverted to sinus rhythm after intravenous dextrose. Atrial fibrillation has not previously been reported as a complication of hypoglycaemia in insulin-dependent diabetic patients.
\end{abstract}

\section{Introduction}

Hypoglycaemia is a common and frequently serious complication of insulin therapy. Approximately $10-$ $15 \%$ of insulin-treated diabetic patients have at least one episode of hypoglycaemic coma each year. ${ }^{\prime}$ We describe two young insulin-dependent diabetic females who presented with severe hypoglycaemia associated with atrial fibrillation which reverted to sinus rhythm after intravenous dextrose.

\section{Case reports}

Case 1

A 31 year old insulin-dependent diabetic woman, who had been diabetic for 12 years on an insulin regimen comprising Neusulin (Wellcome) and Hypurin Protamine Zinc (Weddel) was brought to the Accident and Emergency Department having been found unconscious. Severe hypoglycaemia (plasma glucose $<1 \mathrm{mmol} / \mathrm{l}$ ) was confirmed using a Yellow Springs Glucose Oxidase Analyser. Her pulse was irregular and blood pressure was $110 / 70 \mathrm{~mm} \mathrm{Hg}$. Electrocardiogram (ECG) demonstrated atrial fibrillation with ventricular rate $60-90 / \mathrm{min}$. Intravenous dextrose restored normal conscious level after 4 minutes and a further ECG an hour after admission showed sinus rhythm with no abnormalities (Figure 1). Her glycaemic control since diagnosis has been satisfactory with glycosylated haemoglobin $\left(\mathrm{HbA}_{1}\right)$

Correspondence: A. Collier B.Sc., M.B. Ch.B., M.R.C.P. Accepted: 26 March 1987 checked 6 monthly since 1983 ranging from $8.4-9.6 \%$ (normal range 6-8\%). She was clinically free of diabetic complications. Thyroid function, autonomic nerve function assessed by standard cardiovascular reflex tests, ${ }^{2}$ chest X-ray and echocardiogram were all normal.

\section{Case 2}

A 33 year old insulin-dependent diabetic woman, who had been diabetic for 11 years and on an insulin regimen comprising twice daily Velosulin and Insulatard (Nordisk) was brought to the Accident and Emergency Department having been found unconscious in bed. Severe hypoglycaemia was found (plasma glucose $<1 \mathrm{mmol} / \mathrm{l}$ ) using a Yellow Springs Glucose Oxidase Analyser. Her pulse was irregular and blood pressure was $120 / 75 \mathrm{~mm} \mathrm{Hg}$. ECG demonstrated atrial fibrillation with ventricular rate $70-90 / \mathrm{min}$. Intravenous dextrose $(25 \mathrm{~g})$ restored normal conscious level after 10 minutes and one hour after admission the ECG had reverted to sinus rhythm with no abnormalities (Figure 2). Auscultation revealed a loud first heart sound and after exercise a soft mid-diastolic murmur. Her glycaemic control had been satisfactory with $\mathrm{HbA}_{1}$ checked 6 monthly since 1983 ranging from $7.9-10.4 \%$. She was clinically free of diabetic complications. Thyroid function and autonomic nerve function assessed by standard cardiovascular reflex tests $^{2}$ were normal. Chest $\mathrm{X}$-ray was normal but echocardiogram revealed mild mitral stenosis, with thickened mitral valve leaflets, normal left atrial diameter and good left ventricular function. 
Before

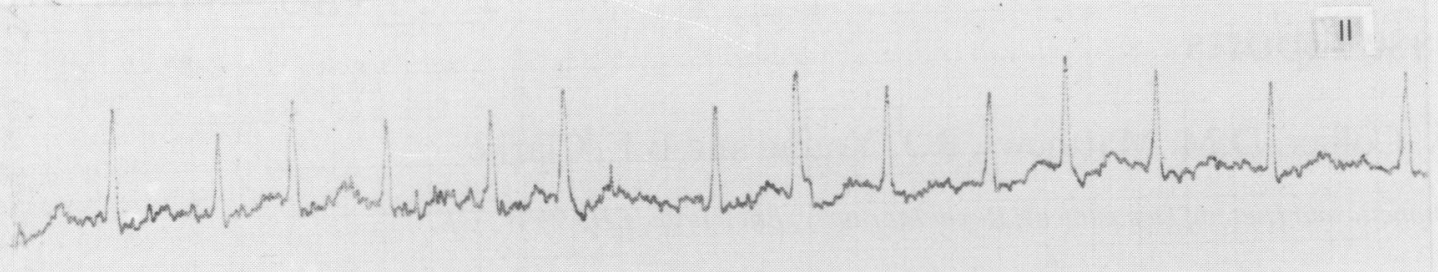

After

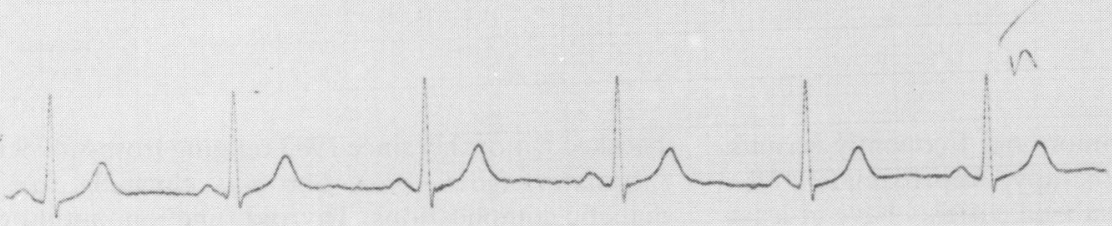

Figure 1 Case 1. Rhythm strip (standard lead II) at presentation and an hour after intravenous dextrose.

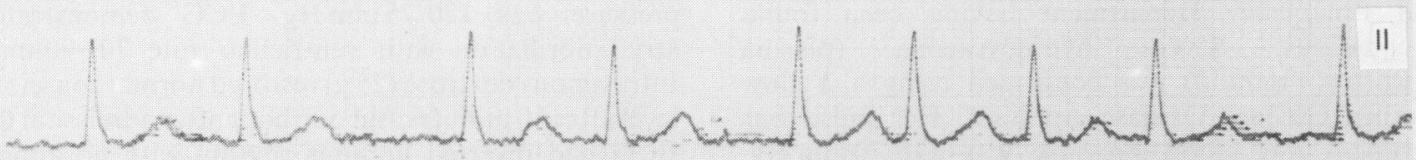

After

Figure 2 Case 2. Rhythm strip (standard lead II) at presentation and an hour after intravenous dextrose. 


\section{Discussion}

Atrial fibrillation precipitated by severe hypoglycaemia has been reported to occur in nondiabetic patients undergoing 'insulin-shock' treatment for psychiatric illness. ${ }^{3}$ Arrhythmias and conduction disturbances occurring as a result of an acute cardiac insult, particularly myocardial infarction, are morc common in diabetic than in non-diabetic patients. ${ }^{4}$ The only arrhythmias previously reported to occur in hypoglycaemic insulin-dependent diabetic patients are atrial and ventricular premature contractions and less frequently nodal rhythms. ${ }^{5}$ The mechanisms by which hypoglycaemia induces such arrhythmias are unknown but may include the direct effect of hypoglycaemia, hypokalaemia, and increased secretion of noradren-

\section{References}

1. Matthews, D.M., Patrick, A.W., Collier, A. et al. Awareness and use of glucagon amongst insulin-treated diabetics. $\mathrm{Br}$ Med J 1986, 293: 367-368.

2. Ewing, D.J., Campbell, I.W. \& Clarke, B.F. Assessment of cardiovascular effects in diabetic autonomic neuropathy and prognostic implications. Ann Intern Med 1980, 92: 308-311.

3. Goldman, D. The electrocardiogram in insulin-shock. Arch Intern Med 1940, 66: 93-108.

4. Henning, R. \& Lundman, T. Swedish Cooperative CCU Study. A study of 2008 patients with acute myocardial aline $e^{5}$ on a possible background of specific myocardial disease, 'diabetic cardiomyopathy' ${ }^{6}$ and cardiac autonomic neuropathy. ${ }^{2}$

Although Case 2 had mild mitral stenosis, which is well recognized to be associated with atrial fibrillation, it appears nevertheless that it was the severe hypoglycaemia that provoked the transient atrial fibrillation. Atrial fibrillation has not been reported before as a complication of hypoglycaemia in insulindependent diabetic patients.

\section{Acknowledgements}

We are grateful to Miss C Mackay for typing the manuscript and Ms J. Miller of the British Diabetic Association for undertaking a literature search.

infarction from twelve Swedish hospitals with coronary care unit. Part I: A description of the early stage. Part II: The short-term prognosis. Acta Med Scand 1975, 198 (Suppl 586): 1-64, 1-35.

5. Shimada, R., Nunoi, K. \& Takeshita, A. Arrhythmia during insulin-induced hypoglycaemia in a diabetic patient. Arch Int Med 1984, 144: 1068-1069.

6. Regan, T.J., Lyons, M.M., Ahmed, S.S. et al. Evidence for cardiomyopathy in familial diabetes mellitus. $J$ Clin Invest 1977, 60: 885-899. 